\begin{tabular}{|c|c|c|}
\hline Received 25.12.2021 & \multirow{3}{*}{ Research Article } & \multirow{3}{*}{$\begin{array}{c}\text { JOTS } \\
6 / 1 \\
2022: 7-20\end{array}$} \\
\hline Accepted 31.12.2021 & & \\
\hline Published 01.01.2022 & & \\
\hline
\end{tabular}

\title{
Dağlık Altay Yazıtlarından Kuray I (A 4) Üzerinde Yeni Bir Okuma ve Anlamlandırma
}

\section{A New Reading and Interpretation on Kuray I (A 4) of the Altai Republic Inscriptions}

\author{
Erhan AYDIN ${ }^{*}$ \\ İnönü University (Malatya/Turkey) \\ E-mail: ayerhan@gmail.com
}

Old Turkic Inscriptions with Turkic runic letters are located on various places of Central and Inner Asia. Texts in Turkic runic letters located on the Altai Republic, a state of the Russian Federation called Altai Republic Inscriptions and their quantity is above a hundred today. In this article, a new reading and interpretation has been made on the text in Turkic runic letters beneath number four, the Kuray I Vessel of the Altai Republic Inscription. On the inscription, presence of a saying stating that drinking, therefore being drunk will cause illnesses was presented to the attention. In the article, evaluations has been made about the words and grammatical structures on the inscription after the "previous readings and interpretations" and "a new reading and interpretation" parts. It was touched upon that one of the drawings beneath the Vessel could be the mark of the dynastic tribe of the Uyghur Khanate, Yaglakar.

Key Words: Old Turkic Inscriptions, Altai Republic Inscriptions, Kuray I, Vessels, Uyghur Khanate.

\footnotetext{
ORCID ID: 0000-0003-4795-7320.
} 


\section{J(ब)}

\section{Giriş}

Türk runik harfli eski Türk yazıtlarıyla ilgili; bir yandan yeni yazıtlar bulunup yayımlanırken öte yandan önceki yazıtlardaki okuma ve anlamlandırmalar yeniden değerlendirilmektedir. Bu bakımdan Türk dilinin ilk yazılı belgeleri olan eski Türk yazıtlarıyla ilgili çalışmaların sayısı da günden güne artmaktadır.

Eski Türk yazıtlarının bulunduğu coğrafyalardan biri, bugün yüzün üzerinde yazıta ev sahipliği yapan Rusya Federasyonu'na bağlı Dağlık Altay Cumhuriyeti'dir. Dağlık Altay Cumhuriyeti sınırları içerisinde ele geçen yazıtlar, G. İ. Spasskiy'in 1818 yılında yayımlanan Sibirskiy Vestnik'. Çast I: Drevnosti Sibiri başlıklı çalışmasından beri bilinmektedir. 1865 yılında Katandı köyü yakınlarındaki bir kurganda yapılan kazılarda gümüş bir kabın altında Türk runik harfli bir metin olduğu fark edilse de bu metin, Radloff un ilgisini çekmez, ancak daha sonra P. M. Melioranskiy tarafından işlenir (Nevskaya, 2011: 10; Erdal \& Kubarev, 2019: 230). Sonraları bölgede araştırma yapan, özellikle arkeoloji heyetleri sayesinde daha fazla yazıt bulundu. Yeni bulunan yazıtların yanında, önceki yazıtlarla ilgili farklı okuma ve anlamlandırma önerileri getiren araştırmalar da yapıldı. Ancak, Dağlık Altay yazıtları ile ilgili ne denli çok çalışma bulunsa da Moğolistan'da bulunan büyük kağanlık ve beylik yazıtları kadar ilgi görmediğini eklemek gerekir. Bundaki en büyük neden, az satırlı olması ve özellikle okuyuşların anlamlı bir birlik ifade etmemesi olarak görülebilir.

Bu makalede 4 numara ile bilinen, Kuray I maşrapasının dibinde bulunan Türk runik harfli metnin yeni bir okuma ve anlamlandırılması yapılacaktır.

\section{Kuray I (A 4) Yazıtı ve Yazitla İlgili Önceki Okuma ve Anlamlandırmalar}

Türk runik harfli metnin bulunduğu Kuray I maşrapası, 1935 yılında Tadila yolunda, Kuray yakınlarında S. V. Kiselëv tarafından yürütülen bir kazıda ele geçmiştir. Gümüşten yapılmış bu kap, bugün Moskova Devlet Tarih Müzesinde korunmaktadır (Tibıkova et al., 2012: 117; Vasilyev, 2013: 36). Maşrapanın altında bulunan ve oldukça açı bir biçimde seçilebilen harflerin teşhisi, dolayısıyla ilk çizimi, okunuşu ve anlamlandırılması Yevtyuhova ve Kiselëv tarafından yapılmış olsa da ancak harflerin teşhisi çok farklıdır. Bundaki en büyük neden, harflerin 


\section{Nol}

içinden geçen ve büyük bir olasılıkla süsleme amacıyla yapılmış zikzak biçimli çizgilerin harflere ait sanılması olmalıdır.

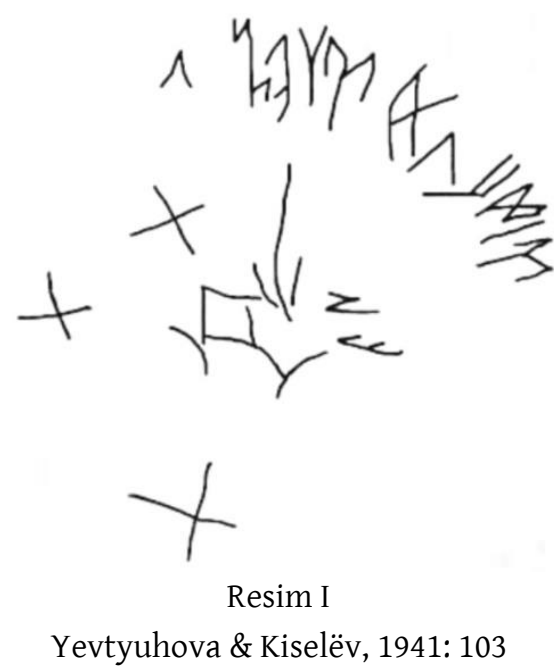

Maşrapanın dibindeki metin ile ilgili önceki okuma ve anlamlandırmalar, tarih sırası ile aşağıda verilmiştir:

L. A. Yevtyuhova ve S. V. Kiselëv:

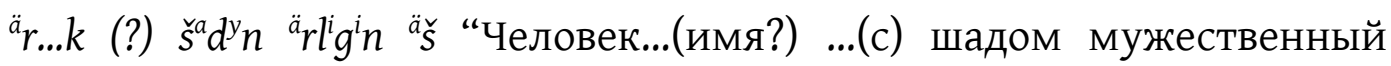
спутник = Adam ... (isim?) ... (ile) Şad'ın cesur arkadaşı."

ök “почет или мудрый = Onur ya da bilge” (1941: 103).

A. K. Borovkov:

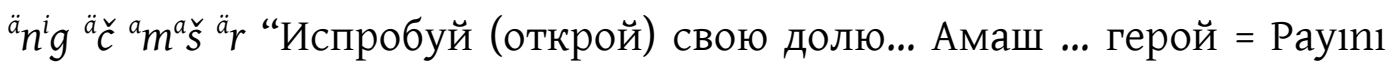
dene (keşfet) ... Amaş ... kahraman" (1963: 193).

V. A. Koçeyev:

Maşrapa hakkında bilgi verildikten sonra, üzerinde yapılmış çalışmalar sıralanır. Maşrapa veya maşrapanın dibindeki yazı ile ilgili çizim ve fotoğraf bulunmaz (2006: 25).

Tibikova et al.:

1) $(\ddot{a}) r(e) \check{s}(i) m(e) l k(i) \check{s}(i) m(\ddot{a}) r l(i) g(\ddot{u}) n(u) n(a) \check{s} !$ “Мои спутники-воины, народ моего племени, достигните взаимного соглашения с этими людьми! = Savaşçı kardeşlerim, kabilemin insanları, bu insanlarla karşılıklı bir anlaşmaya variyorlar!"

2) ög “мать (или мысль, размышление)=anne (veya düşünce, yansıma)”. 


\section{J(ब)}

Tıbıkova vd. notlarında, Eski Türkçede -lXgUn ekinin kullanımıyla ilgili olarak Erdal 2004: 180'e gönderme yapar (2012: 118).

D. D. Vasilyev:

Vasilyev, maşrapa ile ilgili bilgi verdikten sonra, önceki okuyuş ve anlamlandırmalara kısaca değinir, ancak okuma ve anlamlandırma yapmaz (2013: 35-37).

Konkobayev et al. :

1. (e)r $(e)$ şlik $k(i) s ̧(i) m(e) r l(i) g(i) n(e) s ̧$ "Er, eş olmaya layık hanımım, erli olan eş."

2. ög "Anne"

Konkobayev et al., notlarında Tıbıkova et al.'nn $m$ olarak belirlediği işaretin, papyon kravat biçimli işaret olduğu kanaatindedir (2015: 24).

E. Mozioğlu:

Mozioğlu, çalışmasında Tibıkova et al.'in katalogundaki okuma ve anlamlandırmaları verdiği için Kuray I için de yalnızca katalogdaki okuma ile Rusça anlamlandırmanın Türkçe çevirisini verir (2016: 285-286).

\section{Yeni Bir Okuma ve Anlamlandırma}

Maşrapanın altındaki Türk runik harfleriyle yazılmış metinde, harfler arasında, güçlü bir olasılıkla süsleme amacıyla yapılmış çok sayıda zikzak biçimli çizgi, harflerin yanlış teşhis edilmesine neden olmuş, dolayısıyla da çok açık bir metin, zorlama ile türlü biçimlerde okunmuş ve anlamlandırılmaya çalışılmıştır. Türk runik harfli metnin transliterasyonu, transkripsiyonu ve Türkiye Türkçesine aktarımı şöyledir:

\section{Transliterasyon:}

1. rsslksmsrsygnNS

2. $\ddot{w} g$

\section{Transkripsiyon:}

Metinde ünlü işaretleri hiç kullanılmadığı için aşağıda bulunan transkripsiyonda ünlüler parantez içerisinde gösterilmiştir: 


\section{0}

1. $(e) r(\ddot{u})_{s ̧} s(i) l(i) k(\dot{e}) s(i) m(e) s(\ddot{u}) r s(e) \eta(i) g(i) n(u) n(a)_{s}$

2. ög

\section{Anlamlandırma:}

1. Çok sayıda pâk (temiz) dostum; sarhoş olursan hastalığını (önceden) kabullen.

2 Anne?

\section{Okuma ve Anlamlandırma İle İlgili Değerlendirme}

Metinde geçen sözcük ve dilbilgisi yapılarıyla ilgili ayrıntı şöyledir:

\subsection{Erüş 'Çok, çok sayıda'}

G. Clauson 'many, numerous' anlamılla verdiği sözcüğün, üküş 'çok' ile birlikte daha sık kullanıldığını belirtir ve Eski Uygur Türkçesinden örnekler verir. Özellikle Uigurica II $(16,14)$ 'den verdiği edgü kılınç erüş mü "are those good deeds numerous? = Bu iyilikler çok mu?" cümlesi, sözcüğün anlaşılması için iyi bir örnek olarak değerlendirilebilir. Clauson ayrıca, Kutadgu Bilig'in 4247. beytinde bulunan ve Arat'ın uruş 'vuruş, savaş' olarak okuyup anlamlandırdığı sözcüğün de ürüş olabileceğini ihtiyatla belirtir (1972: 239a).

Kutadgu Bilig 4247:

Tepizlik bolur bu kapugda öküş

Tepiz kayda erse tütüş ol uruş (Arat, 1979: 427).

"Bu saray kapısında birbirini çekememek çok olur; nerede çekememek olursa, orada kavga eksik olmaz.” (Arat, 1985: 307).

Sözcüğün, Dîvânu Lügâti't-Türk'te tespit edilmemiş olması, sözcüğün unutulmaya başladığına işaret olarak değerlendirilebilir. Sözcüğün Eski Uygur Türkçesi metinlerindeki kullanım alanı ve örneklerin çeşitliliği hakkında krş. (Wilkens, 2021: 121).

Buna göre; arkasındaki silik sözcüğünün sıfatı durumunda bulunan erüş, Eski Uygur Türkçesi metinlerindeki örneklerden de anlaşılacağı üzere, Eski Türkçenin ikinci evresinde sıklıkla kullanılmıştır. Eski Türk yazıtlarında geçmemiş olması tuhaf olmakla birlikte, aşağıda da sözü edileceği üzere, eğer bu 
kap, dolayısıyla yazılı metin, Uygur Kağanlığı dönemine ait ise, bu durumda 'çok, çok sayıda' anlamındaki erüş sözcügü̈nün kullanılmış olduğu pekâlâ düşünülebilir.

\subsection{Silik 'saf, temiz'}

Çok iyi bilinen ve üzerinde çok tartışılmış sözcüklerden biridir. Türk runik harfli eski Türk yazıtlarında toplam dört kez (Köl Tegin doğu 7 ve 24, Bilge Kağan doğu 7 ve 20) geçen sözcük, yaygın kanaat olarak eşilik 'hanımefendiliğe layık' olarak okunup anlamlandırılmaktadır. Hem fikir vermek hem de silik/eşilik okunması ile ilgili gelinen noktanın daha iyi anlaşılabilmesi açısından, Köl Tegin ve Bilge Kağan yazıtlarında toplam dört kez geçen sözcügün, önceki okuma ve anlamlandırmaları ve sözcükle ilgili yapılan değerlendirmeler aşă̆ıya çıkarılmıştır:

Radloff 1895: silik ‘rein'. (46-47 ve 55). Sözlükte silik ‘rein' (134).

Thomsen 1896 (2002): silik kız “öz kızları, temiz kızları” (130, 144-145).

Thomsen 1935: 'pâk' (100 ve 102).

Orkun 1936: silik 'pakize' (32). Sözlükte: 'temiz, tatlı dilli, yakışıklı, pâkize (1941: 98).

Karamanlıŏlu 1966: Karamanlıŏlu, ibarenin paralelinde beglik urı ogul bulunmasını dikkate alarak (< ? + lik) kalıbında düşünür; işilik 'prenses olacak, bey hanımı olmaya layık' olarak okuyup anlamlandırır.

Tekin 1968: eşilik < Uyg. eşi, işi ‘hanım’ sözcüğünden -lik eki ile türetilmiş sifat sayar. (106 ve 233).

Ergin 1970 (2011): işilik 'hanım olmaya layık' (10 ve 34-35).

Clauson 1972: silik kız ogl:n 'their pure (i.e. virgin) daughters' (679b). silig/silik? sil- 'clean, pure, smooth'. Clauson, ayrıca en erken dört örnekte ikinci ünlünün yazılmamış olmasını, -ü- olabileceği yönünde de değerlendirmek gerektiği kanaatindedir (826b).

Gabain 1988: silig 'arı, temiz, bakire' (294).

Tekin 1988: Tekin, notlarında sözcüğün eşilik biçimiyle ilk kez 1968 yılında yayımlanan gramerinde okuduğunu ve eski Uygur Türkçesi metinlerinde geçen 
eşi, işi 'hanım' sözcüğünden -lik eki ile türemiş bir sıfat olduğunu belirtir. Clauson'un silig, silik 'pure, virgin' < sil- 'to clean' (1972: 826b) anlamiyla vermesini eleştirir. Ayrıca çağdaş Türk yazı dillerinden verdiği örneklerin de silik değil, silig biçiminden geliştiğini belirtir ve beglik urı ogul eşilik kız ogul ibaresinin paralelizm gereği eşi-lik olmasının daha doğru ve mantıklı olduğunu öne sürer. (84).

Ölmez 1998: Karamanlıoğlu'nun görüşünü kesinlikle savunur ve sözcüğün sil- fiilinden türetilmiş olamayacağını, dolayısıyla çağdaş Türk yazı dillerindeki biçimlerin de silig sözcüğünden geliştiğini ve artık silik/eşilik tartışmasına gerek kalmadığını ifade eder (4-6).

Berta 2004: eşilik (143, not 1135-1136 ve 194).

Tekin 2003: eşi 'hanım, hanımefendi' (244).

Sertkaya 2011: Sertkaya, Uyuk-Arjan (E 2) yazıtının ilk satırındaki eşim sözcüğünü eşi 'eş, zevce' anlamında düşünerek Köl Tegin ve Bilge Kağan yazıtlarında dört kez geçen eşilik ile birleştirmek ister ve dolayısıyla silik/eşilik konusuna da değinir. (29 ve not 2 ve 3).

Sertkaya \& Butanayev 2011: Sertkaya, Türk runik harfli maşrapalarla ilgili çalışmasında, Kuray I maşrapası hakkında da bilgi verir ve yazıtla ilgili yapılan çalışmaları sıralar. (120-121).

Ölmez 2013: éşilik 'hanımefendiliğe yakışır' (83, 85, 133, 147); èşilik 'sultanlığa yakışır' $(95,98,135,150)$.

Ercilasun 2016: işilik 'hanım olmaya layık' (508-509, not 37 ve 41). Sözlükte ise; 'hanım (boy beyinin eşi) olmaya layık' (680).

Şirin 2016: (ä)şil(i)k (623, 625, 631, 633). Sözlükte, eşilik ‘hanım olmaya layık, hanımefendi' (728).

Aydın 2017: eşilik 'hanım olmaya layık' (53, 59, 82, 87).

Kaya 2020: Kaya, silik/eşilik okunmasındaki tartışmalara fazla girmeyip Karamanlığlu'nun makalesi ile bu sorunun çözülmüş gibi göründüğünü ve dolayısıyla isi/işi sözcüğünün ne olabileceği üzerinde durur. Sonuç bölümünde ise esşilik okuyuşundaki işi sözcügünün isi olarak okunup kisi ile birleştirilebileceği; 


\section{ग(৫)}

anlam bakımından ise 'kadın, hanım' anlamı yanında, 'kadın yönetici' gibi idari bir unvanı da karşılamış olduğu kanaatini belirtir (24).

Yukarıda verilen okuma ve anlamlandırmalardan; Köl Tegin ve Bilge Kağan yazıtlarından elde edilen dört örneğin önceleri silik, ardından eşilik okunmasında, Eski Uygur metinlerinde geçen eşi 'hanım' sözcüğünün önemli bir etken olduğu sonucu çıkarılabilmektedir. Eşi 'hanım' sözcüğüyle ilgili ayrıntı için bk. (Röhrborn 2000/2019).

Sözcük, Köl Tegin doğu 7'de sIlk; Köl Tegin doğu 24, Bilge Kağan doğu 7 ve Bilge Kağan doğu 20'de ise slk olarak yazılmıştır. Buna göre; Köl Tegin doğu 7'deki yazımda, ilk hecedeki I ünlüsü yazılmış; öteki üç örnekte ise ünlüler yazılmamıştır. Bu yazım, Kuray I maşrapasındaki ünlüsüz slk yazımı ile de birebir örtüşmektedir. Dolayısıyla, uzun tartışmalara sahne olan silik mi eşilik mi okuyuşunun yeniden düşünülmesinde yarar bulunduğu açıktır. Ayrıca, Clauson'un ifade ettiği gibi; silik sözcüğünün ikinci hecesinde yazılmamış bir ünlü de söz konusu olabilir.

\subsection{Eş̧ 'dost'}

Türk runik harfli yazıtlar döneminden itibaren bilinen bir sözcüktür. Bugün Türkiye Türkçesinde sıkça kullanılan ve hem erkeğe hem de kadına göre anlam ifade eden eş sözcüğünün asıl anlamının 'dost, müttefik' olduğu bilinmektedir. Sözcük, asıl anlamının mecazlaşmasından 'karı veya kocaya göre eş' anlamını kazanmış olmalıdır. Bu sözcüğün II. Türk Kağanlığı döneminin büyük kağanlık ve beylik yazıtlarında tespit edilmemiş olması da ayrıca ilginçtir. Sözcük, ağırlıklı olarak Uygur ve Yenisey yazıtlarında tespit edilmiştir. Sözcüğün geçtiği yerlerden birkaçı şöyledir:

Şine Usu doğu 12: Ew barkınt [a] ermiş yelmesin eş̧ yérinerü ıdmış yelmesin meniy er anta basmış tıl tutmış "evinde barkında imiş. Öncü birliğini, müttefiklerin (bulunduğu) yere göndermiş. Öncü birliğine, benim askerim orada saldırmış, muhbirleri ele geçirmiş." (Aydın, 2018: 52); Şine Usu güney 1: Éşine er kelti karlok esşine kelmedök tédi "Müttefiklerinden adam geldi. "Karlukların müttefiklerinden (kimse) gelmedi” dedi." (Aydın, 2018: 52); Begre (E 11) 8: Antlıg adaşım a antsızda edgü eş̧im e adrıldım a "Ant içtiğim yoldaşım, ant ile bağlı olmayan iyi eşimden, dostumdan ayrıldım." (Aydın, 2019a: 70-71); Oçurı (E 26) yazıtı 10: [Alt]mış er adaşııız elig er edgü eş̧iøiz özüinin alpııız "Altmış er yoldaşınız, elli er dostunuz, kendiniz, yiğitleriniz" (Aydın, 2019a: 100).

\subsection{Esür- 'sarhoş olmak'}




\section{0}

'Sarhoş olmak' anlamındaki şart ve kişi eki ekli esür- fiili, Türk runik harfli eski Türk yazıtlarında tespit edilmemiş idi. Ancak, bu satırların yazarınca yeni bir okuyuşu yapılan Muruy maşrapalarından ikincisinin dibindeki Türk runik harfli metinde esürser biçimiyle bir kez tespit edilmiştir. Krş. Aydın, 2021. Dolayısıyla esür- fiili bir kez ele geçmiş olmaktadır. Büyük kağanlık ve beylik yazıtları ile, ölen kişi adına dikilmiş mezar anıtlarında 'sarhoş olmak' anlamında bir fiilin geçmiş olması zaten düşünülemez. Ancak Eski Uygur Türkçesi döneminden itibaren sıkça kullanılan ve Türkçenin her döneminde iyi bilinen bir fiil olduğu anlaşılmaktadır. (Clauson, 1972: 251a). Dolayısıyla Muruy maşrapasında olduğu gibi, içki içmenin zararları, iki maşrapanın altındaki iki özlü cümleden açıkça anlaşılmaktadır.

\subsection{Ig 'hastalık'}

Türk runik harfli eski Türk yazıtlarında 'hastalık' anlamındaki ig sözcüğü tespit edilmemiştir. Yine 'hastalanmak' anlamında agrı- fiili üç kez (Bilge Kağan güney 9, Yamaanı Us II ve Talas I) ele geçmiştir. Bu üç örnekten Talas I yazıtındaki katunı a agrırınta? tulı? a kalmış a "hatunu hastalandığında dul kalmış." cümlesindeki agrt- fiilinden agrır biçiminde, geniş zaman sıfat-fiili ekli olarak düşünüldüğünde, doğrudan 'hastalık' sözcüğünü ifade eden isim elde edilebilir. Bunun dışında doğrudan 'hastalık' anlamında herhangi bir sözcük ele geçmemiş̧ir. Clauson, ig sözcüğünün en erken, Eski Uygur metinlerinden itibaren; ancak çok sık görüldüğünü belirtir (Clauson, 1972: 98b-99a). Sözcüğün Türk runik harfli metinlerde ele geçmemiş olması, sözcüğün özel bir durumu ifade eden anlamından dolayı olabileceği gibi, Uygur diyalektolojisi kaynaklı da olabilir. Aşağıda, değerlendirme bölümünde de sözü edileceği üzere; maşrapadaki Uygur Kağanlığı'nın hanedan boyunun belgesi olan damga, maşrapadaki yazı ile damganın Uygur Kağanlığı dönemine ait olabileceğini, dolayısıyla ig sözcüğünün de Uygur söz varlı̆̆ına ait olabileceğini düşündürmektedir.

\subsection{Una-ş 'kabullen!'}

Una- fiili, 2012 yılında yayımlanan Dağlık Altay Yazıtları Katalogu'nun yazarlarınca 'anlaşmaya varmak' anlamıyla önerilmişti (Tıbıkova et al., 2012: 118). Türk runik harfli eski Türk yazıtlarında 'onaylamak, kabul etmek, 
kabullenmek' anlamlı una- fiili iki kez; Uyuk-Oorzak II (E 109) yazıtının 4. satırında er erdem[im] unamaz "Erkeklik kahramanlığımı onaylamadı(lar)." (Aydın, 2019a: 213) ve Tonyukuk yazıtı 2. taş kuzey 11. satırda sü yorllım tédeçi unamay "ordu sevk edelim derse onaylamayın." (Aydın, 2019b: 184) cümlesinde ele geçmiştir. Buna göre; unaş biçimi ise 'kabul et, kabullen' anlamlı emir biçimi olmalıdır.

\section{7. Ög 'anne'?}

Fotoğrafta da açıkça görüleceği üzere, maşrapanın dibinde, orta tarafta ög sözcüğü göze çarpmaktadır. Ancak bunun asıl metinle hem yazı hem de anlam bakımından ilgisi bulunmamaktadır. Ön ünlülü $g$ sesinin yazımından da anlaşılacağı üzere, her iki metin, yazı karakteri bakımından da ilişkili değildir. Tüm naşirlerce ög okunup 'anne' anlamı verilmiştir. Bir maşrapada böyle bir sözcügün bulunması tuhaf olmakla birlikte, ancak iki harflik bu sözcük, başka türlü okumaya ve dolayısıyla da anlamlandırmaya izin vermemektedir.

\section{Değerlendirme ve Sonuç}

Dağlık Altay yazıtlarından 4 numara ile bilinen Kuray I maşrapasının dibinde bulunan Türk runik harfli metnin, zorlama ile elde edilerek bir maşrapaya yazılamayacak kadar tuhaf okuyuş ve anlamlandırmalar içermesi, metin üzerinde yeniden düşünmeye sevk etmiştir. Maşrapanın dibindeki yazının türlü biçimlerde okunup anlamlandırılması, esasen ünlülerin hiç yazılmamasından kaynaklanmaktadır. Metnin okunmasının güç olduğunu, kesinlikle eklemek gerekmektedir. Muruy maşrapasında olduğu gibi burada da içki içilmesinden gelişen sarhoşluğun insana zarar verdiğinden söz edilmiştir. Ancak Muruy maşrapasından farklı olarak bu maşrapada sarhoşluk derecesinde içki içmenin hastalıklara neden olduğu vurgulanmış ve dolayısıyla "sarhoş olursan, hastalıkları da kabullen!" şartlı birleşik cümlesinde, hem kendi çağındaki dostlarına hem de belki maşrapanın sonraki sahiplerine açık bir tavsiyede bulunulmuştur.

L. N. Tıbıkova, İ. A. Nevskaya ve M. Erdal tarafından yürütülen proje kapsamında 2012 yılında yayımlanan katalog ve bu katalogdaki bilgilerin internet ortamına aktarılmış olması, bilim dünyası için kuşkusuz büyük bir kazanç olmuştur. https://www.altay.uni-frankfurt.de/A4/KURAY1_F.JPG 
adresinde bulunan yüksek çözünürlüklü fotoğraf, yazıt üzerinde çalışmaya ve yeni okuma ve anlamlandırma yapmaya imkân tanımıştır. Fotoğrafta da açıkça görüleceği üzere, orta bölümde yer alan çizimlerden biri, Uygur Kağanlığı'nın hanedan boyu Yaglakar damgası olabilir. Altında yazı olmayan birinci Muruy maşrapasının dibinde de benzer bir damga bulunmaktadır. Kuray maşrapasının da Muruy'da olduğu gibi Uygur Kağanlığı dönemine, dolayısıyla sekizinci yüzyıla ait olabileceğini öne sürmek mümkün görünmektedir.

\section{Kaynakça}

Arat, R. R. (1979). Kutadgu Bilig I: Metin. 2. Baskı. Ankara: Türk Dil Kurumu Yayınları.

Arat, R. R. (1985). Kutadgu Bilig II: Çeviri. 3. Baskı. Ankara: Türk Dil Kurumu Yayınları.

Aydın, E. (2017). Orhon Yazıtları, Köl Tegin, Bilge Kağan, Tonyukuk, Ongi, Küli Çor. İstanbul: Bilge Kültür Sanat.

Aydın, E. (2018). Uygur Yazıtları. İstanbul: Bilge Kültür Sanat.

Aydın, E. (2019a). Sibirya'da Türk İzleri, Yenisey Yazıtları. İstanbul: Kronik Kitap.

Aydın, E. (2019b). Türklerin Bilge Atası Tonyukuk. İstanbul: Kronik Kitap.

Aydın, E. (2021). Muruy Maşrapasındaki Runik Yazı Üzerinde Yeni Bir Okuma ve Anlamlandırma. Dil Araştırmaları, 29, 19-30.

Berta, Á. (2004). Szavaimat Jól Halljátok, A Türk és Ujgur Rovásírásos Emlékek Kritikai Kiadása. Szeged: Jate.

Borovkov, A. K. (1963). Yeniseyskiye nadpisi na sosudah. Tyurkologiçeskiye İssledovaniya. Moskva-Leningrad: 190-196.

Clauson, G. (1972). An Etymological Dictionary of Pre-Thirteenth-Century Turkish. Oxford: Oxford University.

Ercilasun, A. B. (2016). Türk Kağanlğı̆ ve Türk Bengü Taşları. İstanbul: Dergâh.

Erdal, M. \& Kubarev, G. (2019). Güneydoğu Altay'daki Sarı-Kobı Yazıtı. Çev. Alimov, R. Hacettepe Üniversitesi Türkiyat Araştırmaları Dergisi, 30, 229-241.

Erdal, M. (2004). A Grammar of Old Turkic. Leiden-Boston: Brill.

Ergin, M. (2011 [1970]). Orhun Abideleri. 45. Baskı İstanbul: Boğaziçi Yayınları.

Gabain, A. von (1988). Eski Türkçenin Grameri. Çev. Akalın, M. Ankara: Türk Dil Kurumu Yayınları. 


\section{ग(৫)}

Karamanlıoğlu, A. F. (1966). ‘Silik’ Sözü Üzerine. In Reşid Rahmeti Arat İçin (pp. 320322). Ankara: Türk Kültürünü Araştırma Enstitüsü.

Kaya, C. (2020). Köktürkçe İsi/İşi Kisi/Kişi Üzerine. Belgü, 4(5), 19-26.

Koçeyev, V. A. (2006). Svod drevnetyurkskih runiçeskih pamyatnikov Gornogo Altaya. Gorno-Altaysk: Ministerstvo Kul'turı RA.

Konkobayev, K. et al. (2015). Altay Cumhuriyeti'ndeki Eski Türk Yaztları Albümü. Astana: Gilım.

Mozioğlu, E. (2016). Altay Yazıtları. In Kormuşin, İ. et al. (Eds.), Yenisey-AltayKirgızistan Yazıtları ve Kâğıda Yazılı Runik Belgeler (pp. 228-311). Ankara: Bilgesu.

Nevskaya, İ. A. (2011). Recently discovered Old Turkic Runic inscriptions in Mountainous Altai. In Ölmez, M. \& Ylldırım, F. (Eds.), Orta Asya'dan Anadolu'ya Alfabeler (pp. 9-20). İstanbul: Eren Yayıncilik.

Orkun, H. N. (1936). Eski Türk Yazıtları I. İstanbul: Devlet Basımevi.

Orkun, H. N. (1941). Eski Türk Yazıtları IV. İstanbul: Devlet Basımevi.

Ölmez, M. (1998). Eski Türk Yazıtları ve Bugünkü Durumu. Çağdaş Türk Dili, 120, 26.

Ölmez, M. (2013). Orhon-Uygur Hanlı̆ı Dönemi Moğolistan'daki Eski Türk Yazıtları. Ankara: BilgeSu.

Radloff, W. (1895). Die alttürkischen Inschriften der Mongolei. St. Petersburg: Buchdruckerei der kaiserlichen Akademie der Wissenschaften.

Röhrborn, K. (2000). Nochmals zu alttürkisch bäg eşi. Folia Orientalia, 36, 275-279. [Türkçesi: Röhrborn, K. (2019). Tekrar Eski Türkçe bäg eşi. Çev. Aris, G. International Journal of Old Uyghur Studies, 1(1), 89-94).

Sertkaya, O. F. \& Butanayev, V. Ya. (2011). Runik Yazılı Maşrapalar Üzerine (8. Hakasya'da Bulunan Runik Yazılı Gümüş Maşrapa. In Ölmez, M. et al. (Eds.), Ötüken'den İstanbul'a Türkçenin 1290. Yll (720-2010) Sempozyumu Bildirileri [3-5 Aralık 2010, İstanbul] (pp. 119-130). İstanbul: İstanbul Büyükşehir Belediyesi Yayınları.

Sertkaya, O. F. (2011). E 2 - Uyuk-Arjan (Tuva) Yazıtı. Turkish Studies, 6(1), 27-34.

Spasskiy, G. İ. (1818). Sibirskiy Vestnik'. Çast I: Drevnosti Sibiri. St. Petersburg: V' Tipografii Ios. Ioannesova.

Şirin, H. (2016). Eski Türk Yazıtları Söz Varlı̆ı İncelemesi. Ankara: Türk Dil Kurumu Yayınları. 


\section{J(O)}

Tekin, T. (1968). A Grammar of Orkhon Turkic. Bloomington: Indiana University.

Tekin, T. (1988). Orhon Yazıtları. Ankara: Türk Dil Kurumu Yayınları.

Tekin, T. (2003). Orhon Türkçesi Grameri. İstanbul: Simurg.

Thomsen, V. (1935). Moğolistan'daki Türkçe Kitabeler. Çev. Özdem, R. H. Türkiyat Mecmuası, 3, 81-119.

Thomsen, V. (2002 [1896]). Orhon Yazıtları Araştırmaları. Çev. Köken, V. Ankara: Türk Dil Kurumu Yayınları.

T1bıkova L. N. et al. (2012). Katalog Drevnetyurkskix Runiçeskix Pamyatnikov. GornoAltaysk: Gorno-Altaysk Gosudarstvenniy Universitet.

Vasilyev, D. D. (2013). Korpus Tyurkskih Runiçeskih Nadpisey Yujnoy Sibiri. Çast' 1: Drevnetyurkskaya Epigrafika Altaya. Astana: Too (Prosper Print).

Wilkens, J. (2021). Handwörterbuch des Altuigurischen Altuigurisch-Deutsch-Türkisch. Göttingen: Universitätsverlag Göttingen.

Yevtyuhova, L. A. \& Kiselëv, S. V. (1941). Otçet o rabotah Sayano-Altayskoy arheologiçeskoy ekspeditsii v $1935 \mathrm{~g}$. Trudı Gosudarstvennogo İstoriçeskogo Muzeya, 16, 75117.

\section{İnternet Kaynakları}

https://www.altay.uni-frankfurt.de/A4/KURAY1_F.JPG (Erişim tarihi: 08.12.2021)

https://www.altay.uni-frankfurt.de/A4/KURAY1_X.PNG (Erişim tarihi: 08.12.2021)

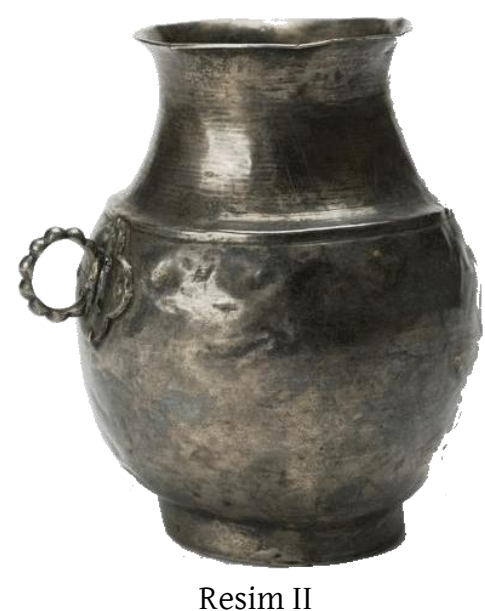

https://www.altay.uni-frankfurt.de/A4/KURAY1_M.PNG 


\section{J(৫)}

\section{ヘ/X(؟)) n \\ \&H $(2$ \\ Resim III}

Tibıkova, Nevskaya ve Erdal'ın harf teşhisleri: (http://www.altay.uni-frankfurt.de/A4/RN4.PNG)

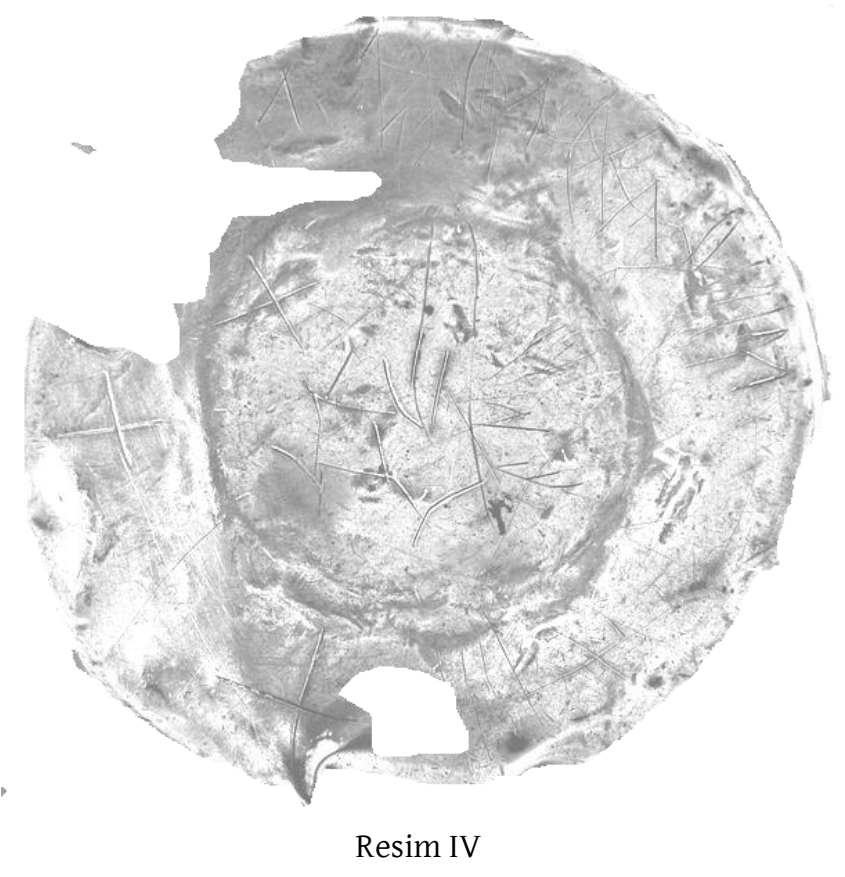

https://www.altay.uni-frankfurt.de/A4/KURAY1_X.PNG

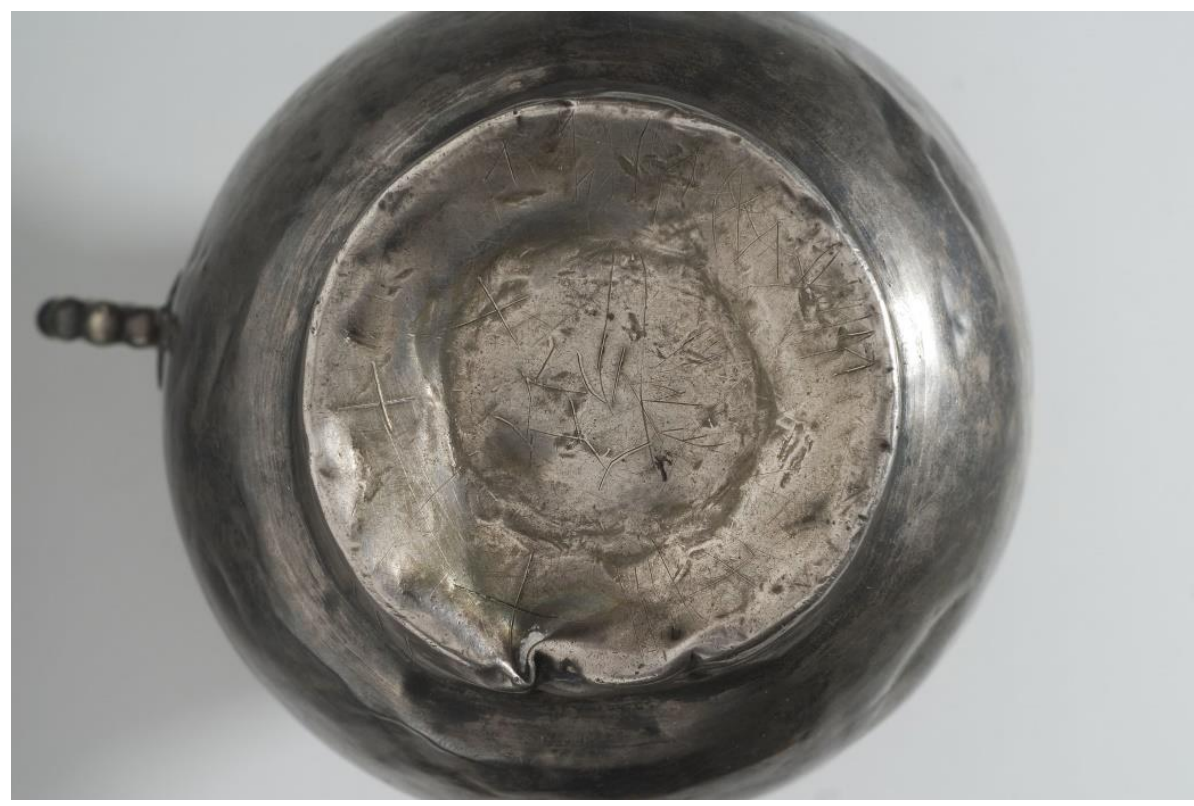

Resim V

Maşrapanın yüksek çözünürlüklü fotoğrafı (https://www.altay.uni-frankfurt.de/A4/KURAY1_F.JPG) 